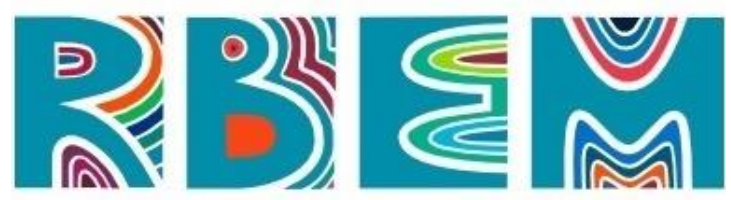

REVISTA BAIANA DE EDUCAÇÃO MATEMÁTICA

\title{
EDITORIAL
}

dol https://doi.org/10.47207/rbem.v1i.10471

\section{Revista Baiana de Educação Matemática: entre histórias, trajetórias iniciais e desafios}

\author{
SILVA, Américo Junior Nunes da \\ Doutor em Educação pela Universidade Federal de São Carlos (UFSCar), professor do Departamento de \\ Educação da Universidade do Estado da Bahia, Campus VII, e do Programa de Mestrado em Educação, Cultura \\ e Territórios Semiáridos (PPGESA/UNEB). Orcid: https://orcid.org/0000-0002-7283-0367. E-mail: \\ ajnunes@uneb.br \\ VIEIRA, André Ricardo Lucas \\ Mestre em Educação de Jovens e Adultos pela Universidade do Estado da Bahia (MPEJA/UNEB), professor do \\ Instituto Federal de Educação, Ciência e Tecnologia do Sertão Pernambucano (IF Sertão-PE), Campus Santa \\ Maria da Boa Vista-PE. Orcid: https://orcid.org/0000-0002-9279-5802. E-mail: sistlin@uol.com.br
}

\section{Editorial}

Fomos surpreendidos em 2020 pela pandemia do novo coronavírus. O distanciamento social, uma das medidas mais eficazes para barrar o contágio da doença, nos fez repensar os ambientes de ensino e aprendizagem e as perspectivas que tínhamos até então. Nesse movimento, foi necessário transformar a nossa casa em nosso local de trabalho; e as diversas demandas profissionais e acadêmicas se juntavam aos inúmeros planejamentos pessoais que foram feitos; com um complicador: tudo tinha que ser feito em casa.

Dentre os planejamentos e demandas para esse ano de 2020 estava à criação de um espaço de divulgação científica, um lugar em que pesquisadores, estudantes e professores, da Educação Básica e do Ensino Superior, pudessem socializar as suas experiências e pesquisas. Era um sonho antigo e mesmo neste ano atípico encontramos um lugar em que pudéssemos fazê-lo realidade. Foi assim que nasceu a ideia que deu forma à Revista Baiana de Educação Matemática (RBEM).

A revista, portanto, nasce enquanto uma ação da terceira linha de pesquisa do Programa de Pós-Graduação em Educação, Cultura e Território Semiáridos (PPGESA). A linha "Campo Educacional, Cultura Escolar e Currículo" acolheu a proposta de criação e, depois de seguir todos os trâmites institucionais, a Gerência de Informática (GERINF) da Universidade do Estado da Bahia, sobretudo o setor responsável pela administração dos 


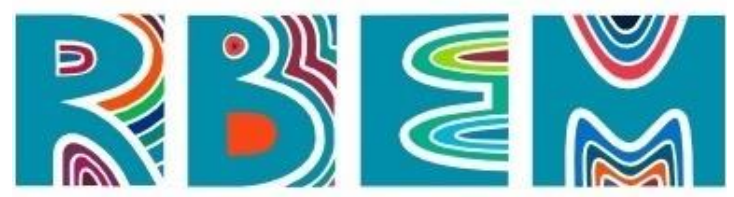

REVISTA BAIANA DE EDUCAÇÃO MATEMÁtICA

periódicos científicos, criou a plataforma.

Nesse ínterim, a Revista Baiana de Educação Matemática constituiu algumas parcerias institucionais: com o Departamento de Educação, Campus VII, da UNEB; e com o Instituto Federal de Educação, Ciência e Tecnologia do Sertão Pernambucano (IF Sertão-PE), Campus Santa Maria da Boa Vista-PE. A RBEM cumpre, desde o seu lançamento oficial, em julho de 2020, a função de divulgar trabalhos que têm como foco o professor que ensina Matemática, sua formação, a realidade e cultura escolar e o ensino e aprendizagem dessa ciência.

Mesmo sendo uma revista jovem, no que se refere ao início de suas atividades editoriais, conseguimos incluí-la em 16 importantes associações, buscadores e indexadores; são eles: i) Google Scholar; ii) Sumários; iii) ResearchBib; iv) Revistas de Livre Acesso; v) Internacional Scientific Indexing; vi) PKP Index; vii) LatinREV; viii) ABEC BRASIL; ix) Eurasian Scientific Journal Index; x) Directory of Research Journals Indexing; xi) Latindex; xii) Diadorim; xiii) Index Copernicus Internacional; xiv) Crossref; xv) Digital Object Identifier (DOI) e xvi) DOAJ. O Directory of Open Access Journals (DOAJ), por exemplo, é um diretório on-line com curadoria da comunidade que indexa e fornece acesso a periódicos de alta qualidade. É frequentemente citado como fonte de qualidade.

Neste primeiro ano de publicação tivemos 22 textos, artigos e relatos de experiência, aceitos e publicados. São trabalhos de professores, estudantes e pesquisadores de inúmeras instituições brasileiras e, também, internacionais. Tivemos trabalhos originados de autores do Distrito Federal (DF), Bahia (BA), São Paulo (SP), Minas Gerais (MG), Pará (PA), Paraíba (PB), Rio de Janeiro (RJ), Espírito Santo (ES), Tocantins (TO) e Estados Unidos (EUA). Assim, apresentamos, a seguir, os 22 textos publicados que constituem o primeiro volume da RBEM.

O primeiro texto intitulado como Ressignificação da Matemática por estudantes de Pedagogia: jogar e reaprender para ensinar, de autoria de Gileade Cardoso Silva e Cristiano Alberto Muniz, busca responder aos questionamentos: Que sentidos subjetivos na aprendizagem matemática são produzidos na formação de estudantes de pedagogia em contextos de jogos matemáticos? Os jogos matemáticos podem contribuir para reconhecer o ser matemático e assim favorecer a formação matemática do estudante de pedagogia? Os autores discutem o jogar como um meio de aprender e ensinar Matemática através do diálogo e da constituição e reconhecimento do Ser Educador Matemático. Por fim, investigam jogos 


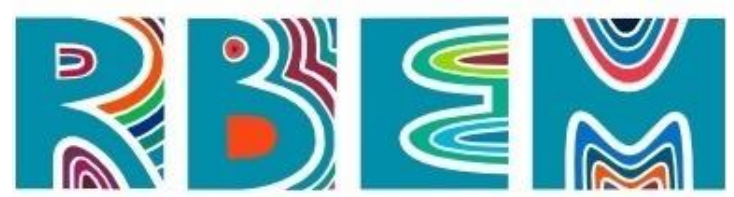

REVISTA BAIANA DE EDUCAÇÃO MATEMÁTICA

matemáticos e a produção de sentidos subjetivos na aprendizagem matemática na formação de estudantes de universidade pública do Distrito Federal-DF.

Leonardo Araújo Suzart e Américo Junior Nunes da Silva, objetivam no texto, intitulado como Ensino de Geometria nos anos finais do Ensino Fundamental: um mapeamento das produções no estado da Bahia, identificar o que se publicou acerca do ensino de Geometria nas três últimas edições do Encontro Baiano de Educação Matemática (EBEM), e entender que implicações tais publicações apresentaram para o ambiente escolar. Vinculase, esse trabalho, ao Laboratório de Estudos e Pesquisas em Educação Matemática da Universidade do Estado da Bahia (UNEB), Campus VII, no município de Senhor do BonfimBA.

An Understanding of Socially-Constructed Knowledge in the Context of Traditional Game-Playing as Theorems-in-Action, terceiro artigo deste volume e de autoria das professoras Ana Lúcia Braz Dias e Juliana Braz Dias, descreve dados de um estudo etnográfico sobre o jogo do Uril, do tipo mancala praticado na ilha de São Vicente, Cabo Verde. Elas interpretam as estratégias de jogo observadas como teoremas-em-ações, construídos socialmente, influenciadas por normas e crenças socialmente compartilhadas, bem como pela construção do conhecimento no nível individual. As autoras também utilizam o conhecimento obtido em um banco de dados gerado por computador para explorar uma sequência de jogadas observadas etnograficamente, verificando sua robustez e as condições necessárias que a tornam uma estratégia vencedora.

O quarto texto intitulado como Modelagem Matemática e Filosofia da Linguagem: algumas articulações, de autoria de Ademir Donizeti Caldeira, Daniana de Costa e Betina Cambi, relata a realização de um estudo sobre como alguns termos que pertencem ao âmbito da Modelagem Matemática estão sendo pautados no pensamento de Ludwig Wittgenstein. A metodologia baseou-se na pesquisa bibliográfica e o material de análise foi constituído por oito artigos científicos que foram publicados em congressos e em periódicos.

Denise França Stehling e Keli Cristina Conti buscam no texto intitulado como Conhecimento Matemático na Educação Infantil: saberes e práticas de professoras num grupo colaborativo, investigar quais os saberes e conhecimentos matemáticos e metodológicos são mobilizados, reconhecidos e ressignificados por professores da Educação Infantil, da Rede Municipal de Ensino de Belo Horizonte-MG, quando se reúnem em grupo 


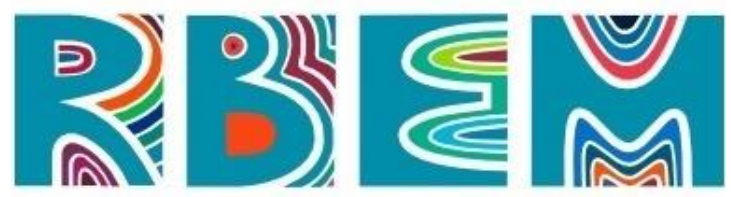

REVISTA BAIANA DE EDUCAÇÃO MATEMÁtICA

de estudos. As autoras destacam que o objetivo é apresentar reflexões sobre o conhecimento matemático que deve ser abordado na Educação Infantil pelo professor e trazer os registros das práticas envolvendo as medidas de tempo e de comprimento, que foram discutidas ao longo de encontros do grupo, destacando os fazeres práticos dos professores.

Pesquisas em Educação Matemática Inclusiva: possibilidades e desafios da utilização de tecnologias digitais e assistivas, sexto artigo desse volume e de autoria de Érica Santana Silveira Nery e Antônio Villar Marques de Sá, tem por objetivo refletir, a partir de uma revisão da literatura, sobre as possibilidades e os desafios na utilização de tecnologias digitais e assistivas para a inclusão de estudantes com Necessidades Educacionais Específicas no ensino de Matemática, na Educação Básica.

No sétimo texto Aprendizagem Matemática por meio da Componente Curricular Desenho Geométrico: algumas considerações tangíveis, o autor Jefferson Correia da Conceição apresenta algumas reflexões acerca de estudos envolvendo os componentes curriculares Desenho Geométrico e Matemática a partir das atividades docentes num contexto acadêmico em sala de aula com licenciandos em Matemática. Já o professor Arthur Gonçalves Machado Júnior e as professoras Cleuma Gonçalves Matos Martins e Talita Carvalho Silva de Almeida, apresentam no texto Um Panorama do Ensino de Estatística em Programas de Pós-graduação em Âmbito Nacional - 2013 a 2017, um estudo sistematizado em programas de pós-graduação stricto senso, a nível nacional, na área do ensino da Matemática. Tem como objetivo identificar como se apresenta nas pesquisas, o ensino da estatística na Educação Básica das escolas brasileiras, bem como refletir acerca da formação inicial e continuada dos professores e quais metodologias têm sido desenvolvidas em suas práticas para possibilitar a melhoria do processo de ensino-aprendizagem em estatística.

O nono texto de autoria de Marcos Luiz Ribeiro e Edda Curi intitulado como Análise quantitativa dos resultados de uma sondagem dos estudantes de $6^{\circ}$ ano com problemas do Campo Multiplicativo, foca nas análises de invariantes operacionais em resolução de problemas do Campo Multiplicativo fundamentada na Teoria dos Campos Conceituais de Vergnaud e chama a atenção para um aspecto da proporcionalidade, em função das dificuldades dos estudantes que estão relacionadas com a Multiplicação Comparativa.

Os artigos As perguntas para desenvolver estratégias: álgebra e resolução de problemas no Ensino Médio e Etnomodelagem: compreendendo o contexto cultural de 


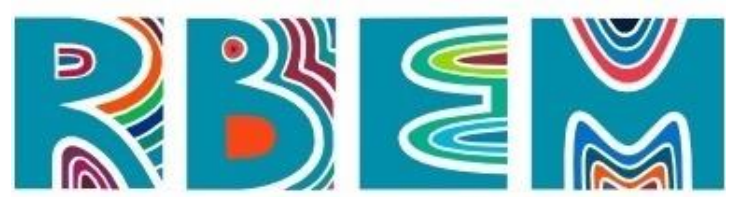

REVISTA BAIANA DE EDUCAÇÃO MATEMÁtICA

produtores de chocolate por meio da elaboração de etnomodelos apresentam recortes de duas pesquisas de mestrado. No primeiro, as professoras Joseane Mirtis de Queiroz e Kátia Maria de Medeiros destacam que o objetivo da pesquisa é investigar como as perguntas podem promover o desenvolvimento de estratégias de resolução de problema algébrico no $3^{\circ}$ ano do Ensino Médio. Já no segundo, o professor Jonas dos Santos e a professora Zulma Elizabete de Freitas Madruga, apontam que o objetivo da pesquisa é analisar o desenvolvimento de uma proposta de ensino, fundamentada na Etnomodelagem, para a construção de etnomodelo para a produção artesanal de chocolate.

Educar para a diversidade é uma das atribuições de qualquer professor(a), não importa a disciplina nem o nível educacional. Partindo dessa premissa Hygor Batista Guse, Tadeu Silveira Waise e Agnaldo da Conceição Esquincalha, no texto O que pensam licenciandos(as) em Matemática sobre sua formação para lidar com a diversidade sexual e de gênero em sala de aula?, discutem o papel do(a) professor(a) (de Matemática) no debate sobre a diversidade sexual e de gênero em sala de aula, procurando desfazer a ideia de que essa discussão tem viés ideológico, como movimentos conservadores afirmam. Questionam a ausência desse tema nos currículos dos cursos de licenciatura, fundamentando-se em pesquisas sobre educação para diversidade e em documentos oficiais brasileiros sobre a formação docente.

As professoras Marcele da Silva Santos e Neide da Fonseca Parracho Sant'Anna, no artigo Reflexões sobre os desafios para a aprendizagem matemática na Educação Básica durante a quarentena, suscitam reflexões sobre os possíveis desafios para o ensino e a aprendizagem matemática na Educação Básica durante a quarentena. O estudo é desenvolvido a partir das diretrizes legais educacionais criadas para validar a substituição das aulas presenciais por aulas em meios digitais enquanto durar a situação de pandemia, atentando para a diferenciação do ensino remoto emergencial e o ensino a distância. Discorrem sobre as dificuldades encontradas pelos alunos nesse momento. Abordam através de situações reais, a superação dos docentes e a importância da formação continuada e tecnológica do professor.

O décimo quarto texto de autoria de Elcio Pasolini Milli e Edmar Reis Thiengo, intitulado como Desenvolvimento do pensamento aritmético de um estudante com deficiência intelectual: uma investigação utilizando o Tampimática, tem por objetivo analisar o desenvolvimento do pensamento aritmético de um aluno com deficiência intelectual, 


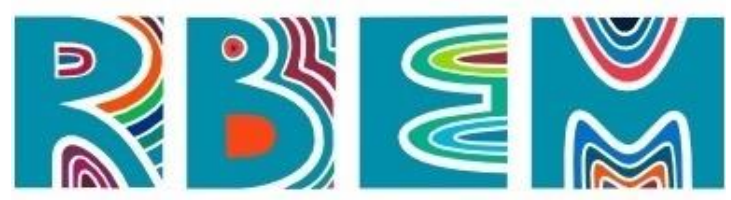

REVISTA BAIANA DE EDUCAÇÃO MATEMÁtICA

particularmente a apropriação da quantificação e da representação numérica, utilizando o Tampimática. Discute as potencialidades da pessoa com deficiência intelectual de acordo com o desenvolvimento cognitivo, no que tange às possibilidades de emancipação do sujeito numa perspectiva dialógica, desenvolvido a partir dos processos de mediação. Aponta discussões sobre o pensamento aritmético, caracterizando as relações entre as construções de novos signos por meio da educação matemática crítica, trabalhada numa perspectiva inclusiva.

O relato Tangram: uma proposta para o ensino de porcentagem a alunos com deficiência intelectual de autoria de Rosângela Pimenta de Sousa e Alcione Marques Fernandes, descreve atividades desenvolvidas no Centro de Ensino Médio de Gurupi-TO, com alunos das primeiras séries que apresentam deficiência intelectual, os quais não possuem um desenvolvimento esperado no conteúdo de porcentagem e com defasagem em conteúdos básicos de Matemática. O objetivo principal, segundo as autoras, é demonstrar, analisar e selecionar práticas pedagógicas de adaptação e flexibilização nos conteúdos de porcentagens, práticas essas que possam surtir efeito para alunos com deficiência intelectual na sala de aula.

Mancala: o uso do jogo como recurso educacional, décimo sexto artigo deste volume e de autoria do professor Claudio Henrique Sales de Souza e da professora Liliana Manuela Gaspar Cerveira da Costa, apresenta as potencialidades didáticas do jogo africano Mancala no ensino de Matemática ao nível do Ensino Fundamental. Foi analisado como o uso de jogos é abordado nos Parâmetros Curriculares Nacionais, na Base Nacional Comum Curricular e por pesquisadores que escreveram sobre este assunto. Também expõe alguns tópicos matemáticos explorados em uma atividade aplicada em duas turmas do $7^{\circ}$ ano do Ensino Fundamental de uma escola da rede privada, onde os alunos responderam um questionário no decorrer do jogo.

Walber Christiano Lima da Costa e Kelvia Nunes da Silva apresentam no texto Construção de Materiais Pedagógicos: contribuições no ensino de Matemática para alunos surdos, os resultados do projeto de iniciação científica, vinculado à Universidade Federal do Sul e Sudeste do Pará (UNIFESSPA). Segundo os autores, tal projeto objetiva a construção de materiais pedagógicos que proporcionem uma aprendizagem mais adequada aos surdos no ensino de Matemática.

Diante da pandemia, em 2020, as aulas presenciais foram suspensas e as escolas tiveram que adotar um modelo que atendesse ao isolamento social e que permitisse a 


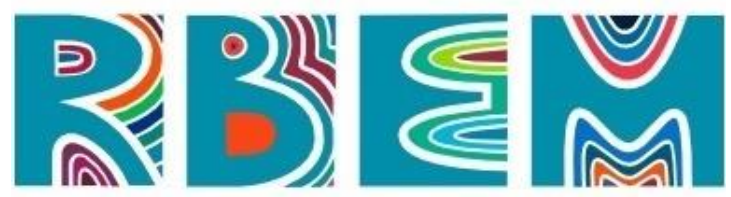

REVISTA BAIANA DE EDUCAÇÃO MATEMÁtICA

continuidade das aulas. Algumas escolas adotaram o Ensino Remoto Emergencial (ERE), outras criaram uma estrutura similar ao ensino a distância (EAD). No texto Avaliação no Ensino Remoto de Matemática: analisando categorias de respostas de autoria de Daniel de Oliveira Lima e Lilian Nasser, relatam a experiência de avaliação com três turmas da $2^{\mathrm{a}}$ série, na Escola SESC de Ensino Médio (ESEM), que adotou o ERE, a partir de uma situação problema, estruturada no ambiente de aprendizagem com referências à realidade. $\mathrm{O}$ modelo usado foi uma pesquisa, que tinha como objetivo promover maior reflexão e compreensão sobre a importância da aplicação da função exponencial na análise do comportamento da infecção pelo vírus.

A reprovação e evasão nas disciplinas de Cálculo nos cursos de graduação vem sendo objeto de pesquisa nas últimas décadas. O texto Discutindo o Método de Ensino por meio da Resolução de Problemas (MERP) de autoria de Angela Biazutti, Rafael Filipe Vaz e Luciano Roberto Andrade, problematiza a aprendizagem de Cálculo e discute a utilização do Método de Ensino por Meio da Resolução de Problemas (MERP) como uma sugestão didática e metodológica elaborada pelo grupo Transição para o ensino de Matemática, mais precisamente para os conteúdos de Cálculo, como por exemplo, funções.

$O$ processo de construção de um material educacional na perspectiva da Educação Matemática inclusiva para um aluno autista, vigésimo texto deste volume e de autoria das professoras Gisele Maria da Fonseca Pinto e Amália Bichara Guimarães, relata a experiência em uma escola regular de Educação Básica junto a residentes do programa de Residência Pedagógica em Matemática da Universidade Federal Rural do Rio de Janeiro, polo Seropédica, no biênio 2018/2019, tendo um aluno autista incluído em uma turma de $8^{\circ}$ ano do Ensino Fundamental II.

Os professores João Caldato e Carlos Augusto Aguilar Júnior autores do texto Argumentação e Prova em Matemática: uma análise dos itens públicos do PISA 2012, analisam os itens públicos do Programa Internacional de Avaliação dos Estudantes (PISA, em inglês) de 2012 que versem sobre argumentação e prova em Matemática. Segundo os autores, estes itens exploram os três processos matemáticos (formular, empregar e interpretar), fundamentais para o desenvolvimento da capacidade de raciocinar e argumentar, e definem o letramento matemático segundo a matriz de referência do PISA.

$\mathrm{O}$ vigésimo segundo texto intitulado como Trigonometry in rural space: 


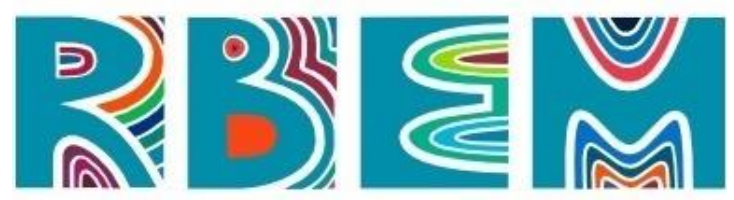

REVISTA BAIANA DE EDUCAÇÃO MATEMÁtICA

implications of contextualized mathematics education de autoria de Charles Maycon de Almeida Mota e Fabrício Oliveira da Silva, busca compreender como as experiências com oficinas pedagógicas de ensino de Matemática em espaço rural favoreceu o ensino e aprendizagem da geometria por licenciandos de Pedagogia e por estudantes do Ensino Fundamental. O texto reflete os contextos da roça, evidenciando como isso pode ser potencializado como lócus para valorização de fazeres na docência que extrapolem os muros da escola e se ampliem pelos contextos de vida de seus estudantes.

Mesmo diante de um cenário atípico [por conta do COVID-19], como dissemos no início deste texto, avaliamos positivamente o ano de 2020, no que tange aos trabalhos editoriais da Revista Baiana de Educação Matemática. Contudo, precisamos agradecer aos membros do conselho editorial, os avaliadores, editores de texto, revisores, autores e leitores da revista: A RBEM chegou aonde chegou pela participação de todos vocês nesse processo. Por isso, o nosso muito obrigado.

\section{Referências}

BATISTA GUSE, H.; SILVEIRA WAISE, T.; ESQUINCALHA, A. da C. O que pensam licenciandos(as) em matemática sobre sua formação para lidar com a diversidade sexual e de gênero em sala de aula? In: Revista Baiana de Educação Matemática, v. 1, p.1-25, e202012, 20 nov. 2020.

BIAZUTTI, A.; VAZ, R. F.; ANDRADE, L. R. Discutindo o Método de Ensino por meio da Resolução de Problemas (MERP). In: Revista Baiana de Educação Matemática, v. 1, p.1-23, e202019, 22 dez. 2020.

BRAZ DIAS, A. L.; BRAZ DIAS, J. An Understanding of Socially-Constructed Knowledge in the Context of Traditional Game-Playing as Theorems-in-Action. In: Revista Baiana de Educação Matemática, v. 1, p.1-25, e202003, 3 ago. 2020.

CALDATO, J.; AGUILAR JÚNIOR, C. A. Argumentação e Prova em Matemática: uma análise dos itens públicos do PISA 2012. In: Revista Baiana de Educação Matemática, v. 1, p.1-24, e202021, 22 dez. 2020.

CALDEIRA, A. D.; COSTA, D. de; CAMBI, B. Modelagem Matemática e Filosofia da Linguagem: algumas articulações. In: Revista Baiana de Educação Matemática, v. 1, p.1-21, e202004, 14 ago. 2020. 


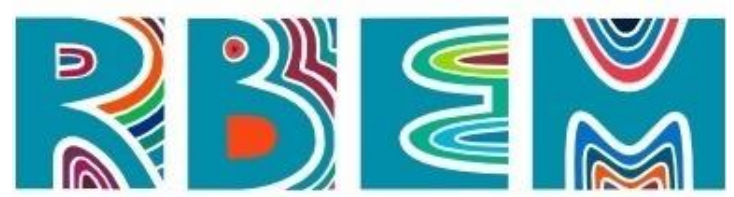

REVISTA BAIANA DE EDUCAÇÃO MATEMÁtICA

CONCEIÇÃO, J. C. da. Aprendizagem Matemática por meio da Componente Curricular Desenho Geométrico: algumas considerações tangíveis. Revista Baiana de Educação Matemática, v. 1, p.1-20, e202007, 29 ago. 2020.

COSTA, W. C. L. da; SILVA, K. N. da. Construção de Materiais Pedagógicos: contribuições no ensino de matemática para alunos surdos. In: Revista Baiana de Educação Matemática, v. 1, p.1-15, e202017, 17 dez. 2020.

LIMA, D. de O.; NASSER, L. Avaliação no Ensino Remoto de Matemática: analisando categorias de respostas. In: Revista Baiana de Educação Matemática, v. 1, p.1-19, e202018, 22 dez. 2020.

MACHADO JÚNIOR, A. G.; MATOS MARTINS, C. G.; SILVA DE ALMEIDA, T. C. Um Panorama do Ensino de Estatística em Programas de Pós-graduação em Âmbito Nacional 2013 a 2017. In: Revista Baiana de Educação Matemática, v. 1, p.1-19, e202008, 31 ago. 2020.

MILLI, E. P.; THIENGO, E. R. Desenvolvimento do pensamento aritmético de um estudante com deficiência intelectual: uma investigação utilizando o Tampimática. In: Revista Baiana de Educação Matemática, v. 1, p.1-17, e202014, 17 dez. 2020.

MOTA, C. M. de A.; SILVA, F. O. da. Trigonometry in rural space: implications of contextualized mathematics education. In: Revista Baiana de Educação Matemática, v. 1, p.119, e202022, 22 dez. 2020.

NERY, É. S. S.; SÁ, A. V. M. de. Pesquisas em Educação Matemática Inclusiva: possibilidades e desafios da utilização de tecnologias digitais e assistivas. In: Revista Baiana de Educação Matemática, v. 1, p.1-24, e202006, 27 ago. 2020.

PINHEIRO, J. M. de Q.; MEDEIROS, K. M. de. As perguntas para desenvolver estratégias: Álgebra e Resolução de Problemas no Ensino Médio. In: Revista Baiana de Educação Matemática, v. 1, p.1-25, e202010, 23 out. 2020.

PINTO, G. M. da F.; GUIMARÃES, A. B. O Processo de construção de um material educacional na perspectiva da Educação Matemática Inclusiva para um aluno autista. In: Revista Baiana de Educação Matemática, v. 1, p.1-23, e202020, 22 dez. 2020.

RIBEIRO, M. L.; CURI, E. Análise quantitativa dos resultados de uma Sondagem dos estudantes de $6^{\circ}$ ano com problemas do Campo Multiplicativo. In: Revista Baiana de Educação Matemática, v. 1, p.1-19, e202009, 28 set. 2020.

SANTOS, J. dos; MADRUGA, Z. E. de F. Etnomodelagem: compreendendo o contexto cultural de produtores de chocolate por meio da elaboração de etnomodelos. In: Revista Baiana de Educação Matemática, v. 1, p.1-21, e202011, 10 nov. 2020. 


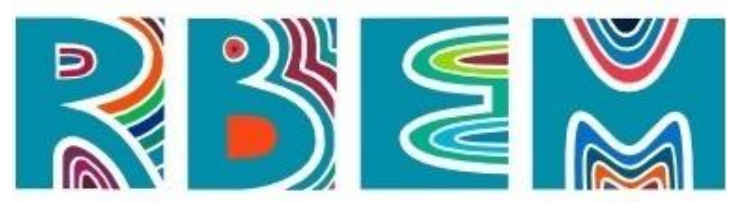

SANTOS, M. da S.; SANT'ANNA, N. da F. P. Reflexões sobre os desafios para a aprendizagem matemática na Educação Básica durante a quarentena. In: Revista Baiana de Educação Matemática, v. 1, p.1-22, e202013, 17 dez. 2020.

SILVA, G. C.; MUNIZ, C. A. Ressignificação da Matemática por estudantes de Pedagogia: jogar e reaprender para ensinar. In: Revista Baiana de Educação Matemática, v. 1, p.1-22 e202001, 22 jul. 2020.

SOUZA, C. H. S. de; COSTA, L. M. G. C. da. Mancala: o uso do jogo como recurso educacional. In: Revista Baiana de Educação Matemática, v. 1, p.1-16, e202016, 17 dez. 2020 .

SOUSA, R. P. de; FERNANDES, A. M. Tangram: Uma proposta para o ensino de porcentagem a alunos com deficiência intelectual. In: Revista Baiana de Educação Matemática, v. 1, p.1-15, e202015, 17 dez. 2020.

STEHLING, D. F.; CONTI, K. C. Conhecimento matemático na Educação Infantil: saberes e práticas de professoras num grupo colaborativo. In: Revista Baiana de Educação Matemática, v. 1, p.1-26, e202005, 14 ago. 2020.

SUZART, L. A.; SILVA, A. J. N. da. Ensino de Geometria nos anos finais do Ensino Fundamental: um mapeamento das produções no estado da Bahia. In: Revista Baiana de Educação Matemática, v. 1, p.1-22, e202002, 22 jul. 2020. 